\title{
Urban materials for comfortable open spaces
}

\author{
Valentina Dessì \\ Politecnico of Milan Dept. BEST, Milan, Italy \\ Tel: +39223995128, Fax: +39223995150, E-mail: valentina.dessi@polimi.it
}

\begin{abstract}
All the elements present in open areas contribute to define the microclimate and they have to be designed to mitigate the microclimate. In particular urban materials have to be selected on the basis of the urban space use and its thermal behavior.

This paper shows the influence of urban pavements and building facades materials on the open spaces environmental performance and on thermal comfort conditions. In order to evaluate the contribution of the materials thermal simulations in dynamic regime were carried out of simplified configurations (corner of squares and streets. The paper shows how the urban space thermal performances change when only one or two walls are considered and if differences occur when the analyzed area is near or far from the wall, as well as when building height changes. This first part of analysis considers the open space as reference case and evaluates how the thermal performances change according to the changing context (from open space to the corner of the square). The second part points out the differences among the materials due to the physical properties, like albedo, thermal capacity and density. The last analysis concerns the evaluation of these configurations in terms of thermal comfort.
\end{abstract}

Keywords: Microclimate mitigation, urban materials, thermal comfort, open spaces.

\section{Introduction}

Pavement and building facades represent the recognizable support of urban space, i.e. the scenario of collective memory and social life built by movements, trading, meetings and communication. These spaces should represent more than the possibility to cross or reach destinations: they should satisfy the users need dealing with the perception of the space [1] [2]. Pavements and facades have another role. Urban space materials, as well as urban morphology, define the urban heat island. Nowadays the insufficient attention to physical properties of materials and the free development of the built environment induce to increase this phenomenon. It affects the unpleasant microclimate in contemporary cities, especially during the summer. It is important to know natural materials properties in order to classify them on the basis of energy performances.

To understand the energy behaviour of materials in urban space an analysis was done comparing energy performance of some urban configurations by changing pavements and facades materials. Thermal simulations in dynamic regime were carried out with the software Solene [3] in order to define the role of materials and observe their behaviour in particular urban contexts. Simulations were done for a latitude of $45^{\circ}$ (Milan, Italy) in a sunny day (clear sky). The microclimate is determined also by the materials' thermal properties and can be evaluated in order to foresee suitable environmental performance and acceptable thermal comfort conditions of urban space, in case of new project or urban renewal.

\section{Methodology}

Thermal simulations in dynamic regime have the advantage of highlighting each element contribute one by one. For this reason it is possible to evaluate the pavement colour impact on energy performance of the urban space as well as the heat capacity. In other words it allows to understand if it is better to pave a square with red granite or wood, with clear or dark stone. 
Cases simulated with Solene and reported in the paper describe the thermal behaviour of specific locations in a urban space (centre of a square, the corner or areas differently oriented) by varying paving and facades materials.

Nevertheless before analysing thermal performance of materials in specific urban configurations, the most common paving materials should be analyzed to better understand differences [4]. To reach this goal we use a urban space not surrounded by buildings. This situation will be next considered as reference case.

Table. 1. Pavements materials used for the simulations. (A is albedo)

\begin{tabular}{|c|c|c|c|c|c|c|}
\hline & $\mathbf{N}^{\mathbf{0}}$ & Material & $\mathbf{c m}$ & $\begin{array}{l}\text { Conductivity } \\
\left(\mathrm{W} / \mathrm{m}^{\circ} \mathrm{C}\right)\end{array}$ & $\begin{array}{l}\text { Specific } \\
\text { heat } \\
\left(\mathrm{J} / \mathrm{kg}^{\circ} \mathrm{C}\right)\end{array}$ & $\begin{array}{l}\text { Density } \\
\left(\mathrm{Kg} / \mathrm{m}^{3}\right)\end{array}$ \\
\hline \multirow{2}{*}{ 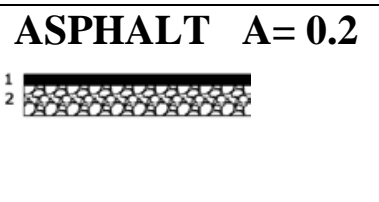 } & 1 & $\begin{array}{l}\text { Wear layer - } \\
\text { asphalt }\end{array}$ & 2.5 & 0.7 & 920 & 2100 \\
\hline & 2 & $\begin{array}{l}\text { Tout venant - } \\
\text { (gravel) }\end{array}$ & 7 & 1.2 & 840 & 1700 \\
\hline \multirow[t]{4}{*}{ STONE $A=0.5$} & 1 & $\begin{array}{l}\text { Red granite slab } \\
\mathrm{A}=0.5^{*}\end{array}$ & $\geq 3$ & 4.1 & 840 & 3000 \\
\hline & 2 & Mortar & $3-4$ & 0,58 & 840 & 1200 \\
\hline & 3 & Hot flush & 15 & 0.94 & 880 & 1800 \\
\hline & 4 & Road-metal & $20 / 40$ & 0.6 & 840 & 1700 \\
\hline \multirow[t]{2}{*}{ * alternative coating } & 1 & Marble $\mathrm{A}=0.8$ & $\geq 3$ & 3 & 840 & 2700 \\
\hline & 1 & Lime $\quad A=0.7$ & $\geq 3$ & 1.5 & 840 & 1900 \\
\hline $\begin{array}{c}\text { PORPHYRY A= } \\
0.3\end{array}$ & 1 & $\begin{array}{l}\text { Cubes of } \\
\text { porphyry }\end{array}$ & 5 & 2.9 & 880 & 2200 \\
\hline \multirow{2}{*}{${ }_{2}$} & 2 & Sand and & 10 & 0,35 & 840 & 1800 \\
\hline & 3 & Road-metal & $20 / 40$ & 0.6 & 840 & 1700 \\
\hline \multirow{5}{*}{ 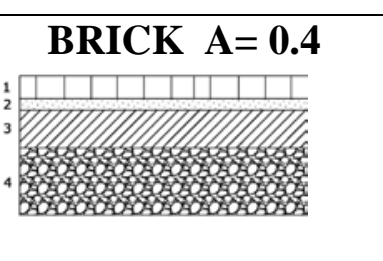 } & 1 & Sestini & 6 & 1.7 & 840 & 2400 \\
\hline & & laterizio & & & & \\
\hline & 2 & Mortar & 2,5 & 0,58 & 840 & 1200 \\
\hline & 3 & Hot flush & & 0.94 & 880 & 1800 \\
\hline & 4 & Road-metal & $20 / 40$ & 0.6 & 840 & 1700 \\
\hline \multirow{3}{*}{$\begin{array}{c}\text { COLORED CLS A= } \\
0.5\end{array}$} & 1 & Slurry & 8 & 1.2 & 880 & 1800 \\
\hline & 3 & Hot flush & 7 & 0.94 & 880 & 1800 \\
\hline & 4 & Road-metal & $\begin{array}{l}20- \\
40\end{array}$ & 0.6 & 840 & 1700 \\
\hline \multirow{3}{*}{$\begin{array}{l}\text { WOOD } \\
\mathrm{A}=0.6\end{array}$} & 1 & Larix stave* & $4 / 5$ & 0.12 & 2700 & 550 \\
\hline & 2 & Joist transverse & & & & \\
\hline & 4 & Road-metal & & & & \\
\hline * alternative coating & & Cedrum stave & $4 / 5$ & 0.19 & 2390 & 700 \\
\hline
\end{tabular}


It's important to keep in mind that with solar radiation, the characteristic with highest impact on thermal behavior is the solar reflection coefficient, the albedo (A), which depends on color and texture [5]. Material surface temperatures on horizontal plan are more close to the solar radiation trend then the air temperature.

A first assessment was done on several stone materials - granite, porphyry, lime stone and marble. Specific heat in stone materials is quite similar, while conductivity and density can be quite different. A second study was done on other urban materials (asphalt, concrete, wood).

The analysis will be completed after evaluating the previous simulations into a urban context. Each urban space, i.e. a square, a road or a courtyard is a distinct system that should be analyzed every time. In this work just parts of urban spaces were considered, like a position close to a w all (dihedral) or the niche (trihedral) representing the corner in a s quare. Simulation results were compared with the reference case (pavement in open space, i.e. without facing buildings).

In order to include geometrical and material aspects in the same analysis the mean radiant temperature MRT was considered, i.e. the all surfaces temperature multiplied by the view factors of buildings and pavement.

The urban space is usually considered "closed", i.e. the sum of view factors is equal to 1 . In this analysis only pavement and facades were considered, (dihedral and trihedral configuration) (fig.1).
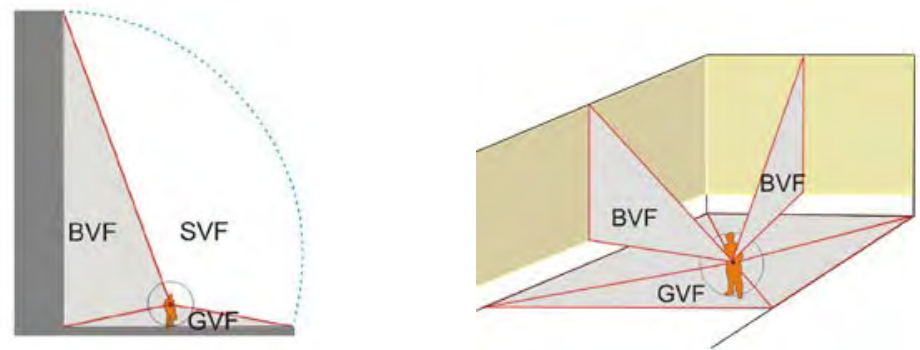

Fig.1: Dihedral and trihedral sections with angles representation for view factors calculations. $B V F=$ building view factor; $G V F=$ ground view factor; $S V F=$ sky view factor $(1-B V F-G V F)$.

Table. 2. Physical characteristics of façade materials used for the simulation

\begin{tabular}{|c|c|c|c|c|c|c|}
\hline & $\mathbf{N}^{\mathbf{0}}$ & Material & $\mathbf{c m}$ & $\begin{array}{l}\text { Conductivity } \\
\left(\mathrm{W} / \mathrm{m}^{\circ} \mathrm{C}\right)\end{array}$ & $\begin{array}{l}\text { Specific heat } \\
\left(\mathrm{J} / \mathrm{kg}^{\circ} \mathrm{C}\right)\end{array}$ & $\begin{array}{l}\text { Density } \\
\left(\mathrm{Kg} / \mathrm{m}^{3}\right)\end{array}$ \\
\hline "LIGHT" & 1 & wooden floor & 2 & 0.15 & 2500 & 560 \\
\hline 1 & 2 & polystyrene & 20 & 0.04 & 1000 & 25 \\
\hline & 3 & wooden floor & 2 & 0.15 & 2500 & 560 \\
\hline MASSIVE & 1 & plaster & 1.5 & 0.9 & 840 & 1800 \\
\hline $\begin{array}{lll}1 & 2 & 1\end{array}$ & 2 & bricks & 20 & 0.8 & 840 & 2000 \\
\hline & 3 & plaster & 1.5 & 0.9 & 840 & 1800 \\
\hline GLASS WALL & 1 & Double glass & 2.2 & 1 & 837 & 3500 \\
\hline
\end{tabular}


The two configurations in the four orientations were analysed and observations were made to understand what happens when the point is near or far from the wall and what happens if the wall is 4 or 20 metres high. It is possible to investigate the role of vertical surfaces, it means to understand what happens when the wall is a glass' one, brickwork (heavy) or highly insulated (light) one, associate to a paving with albedo $\mathrm{A}=0.5$.

\section{Results}

\subsection{Materials' energy behaviour in open space}

The comparison among stone materials shows that the porphyry is the stone with the worst environmental performance because of the high conductivity and relative low density. If we consider only density and conductivity e not the albedo parameter, marble and granite would be quite similar and with best environmental performance (fig.2). During the day surface temperatures would arise over the air temperature $\left(>10^{\circ} \mathrm{C}\right)$ while in the night it would go under air temperature, to about $4-5^{\circ} \mathrm{C}$.

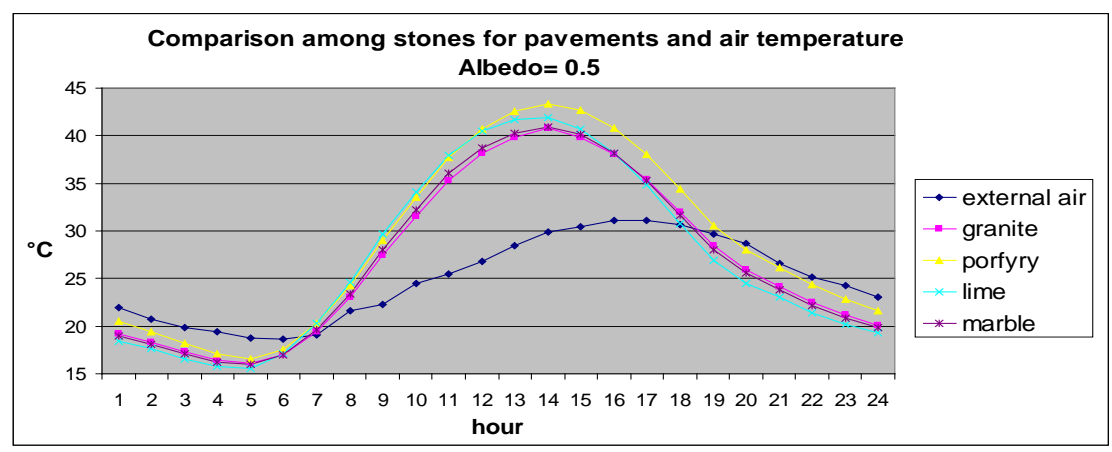

Fig.2: air temperature and stone pavements surface temperature. All stone materials are considered with the same albedo

Lime stone with relative low density and low conductivity has the surface temperature higher than the marble's and granite's ones and during the night it is the coolest material.

Regarding the other materials, wood has the worst performance, few differences if it is citron or larch. The asphalt is similar to the concrete and it isn't the worst material as usual (fig.3).

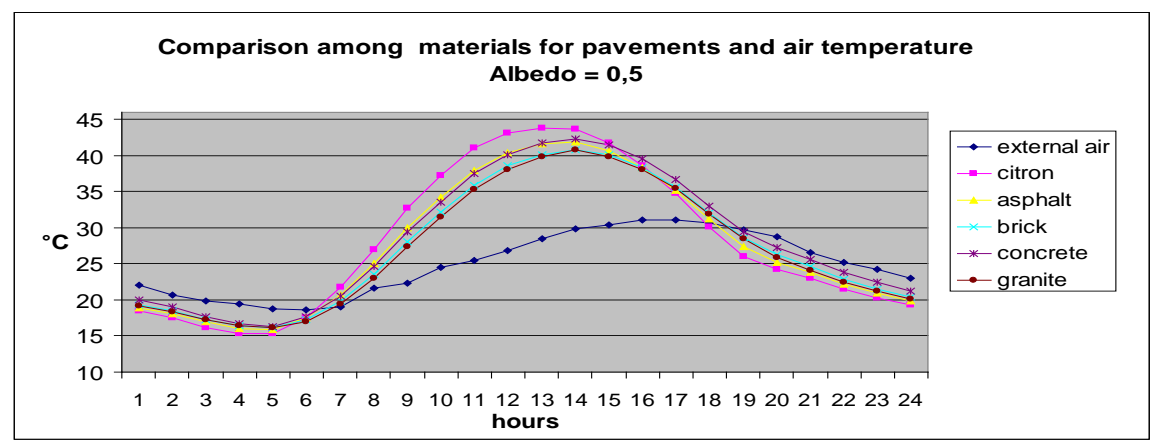

Fig.3: air temperature and surface temperature. All materials are considered with the same albedo

Considering realistic albedo values the red granite temperature is between porphyry and lime stone's ones (fig.4), quite higher than the marbles one $\left(>10^{\circ} \mathrm{C}\right)$. According to [7], it is evident that higher is the albedo, lower is the surface temperature, in spite of the other physical characteristics of the materials. The white marble for instance has the albedo value close to 0.8 and his surface temperature is lower than the air temperature. On the other hand asphalt is absolutely the worst, due to the low albedo. With a simple observation we can confirm that asphalt should be avoided in pedestrian areas. 


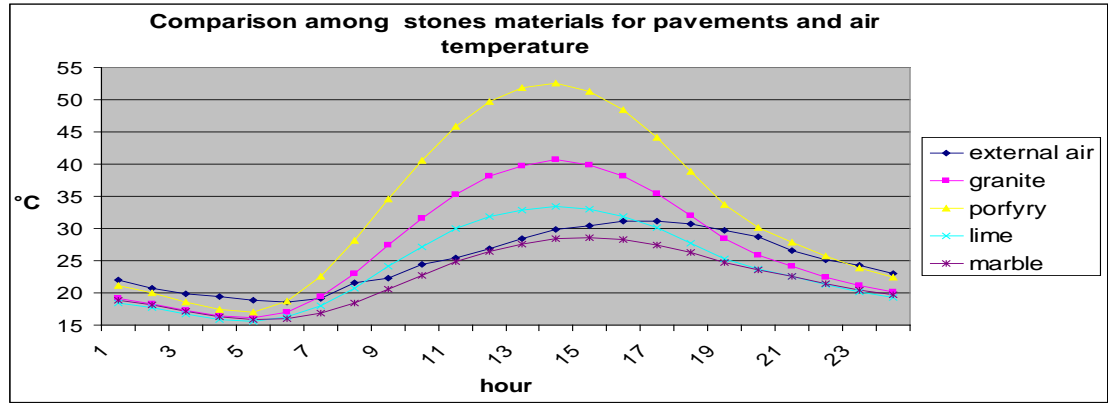

Fig.4: air temperature and stone pavements surface temperature

Wood hasn't good performance as well and if we want to use it, it would be better to paint it otherwise to use it with water as for cool pavements.

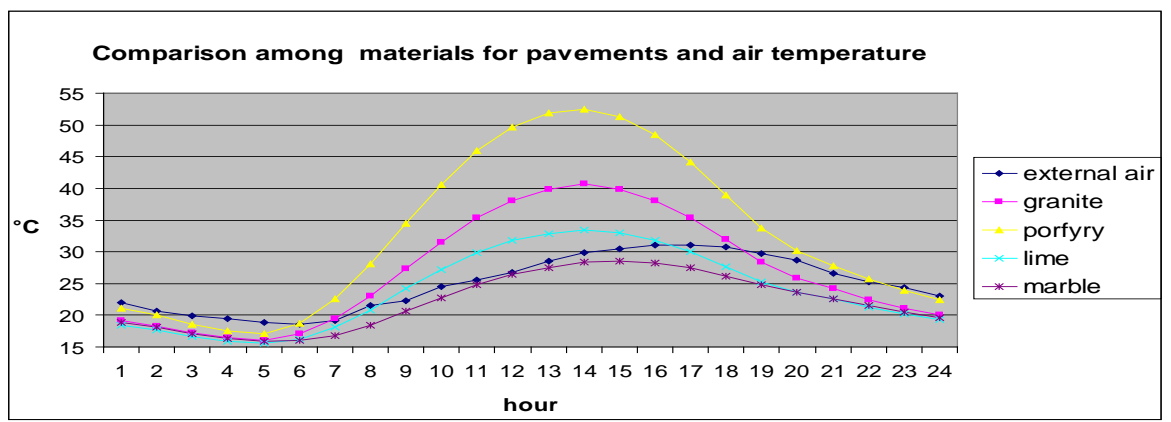

Fig.5: air temperature and pavements surface temperature

In general we can see that during the day the difference between materials and air temperatures could be also about $23^{\circ} \mathrm{C}$ (the higher difference at 2 p.m., in fig.5), but in the night the air temperature is always higher than the pavements materials' one. Figure 5 also shows that even in this case there are significant differences during the day when abig amount of solar radiation is present. In these hours the albedo influence is evident. During the night differences are due to density and conductivity (specific heat is similar for them).

\subsection{Materials' energy behaviour in simplified urban configurations}

The graphs display air and mean radiant temperature in a dihedral and trihedral shape.

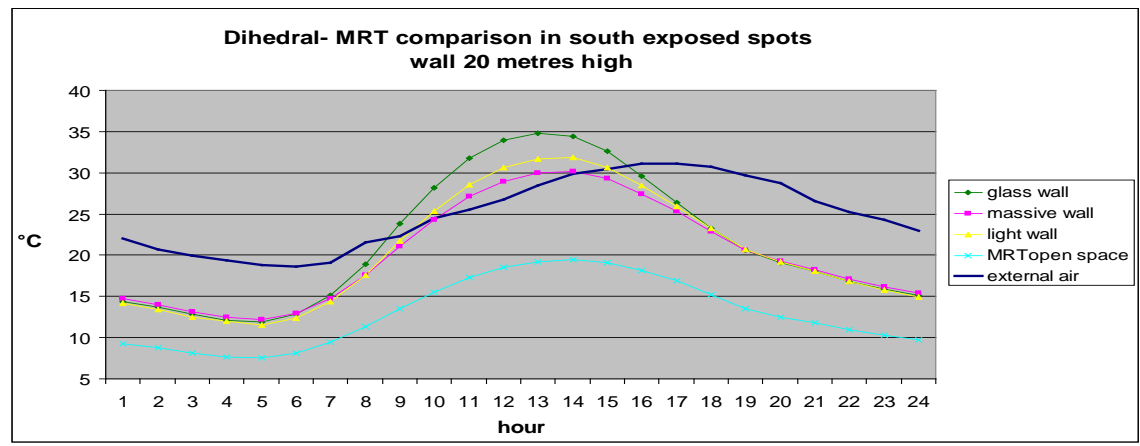

Fig.6: air temperature and mean radiant temperature (MRT) in an open space and dihedrals shape with massive light and glass wall. The point is south exposed 10 metres far from the wall $20 \mathrm{~m}$ high 


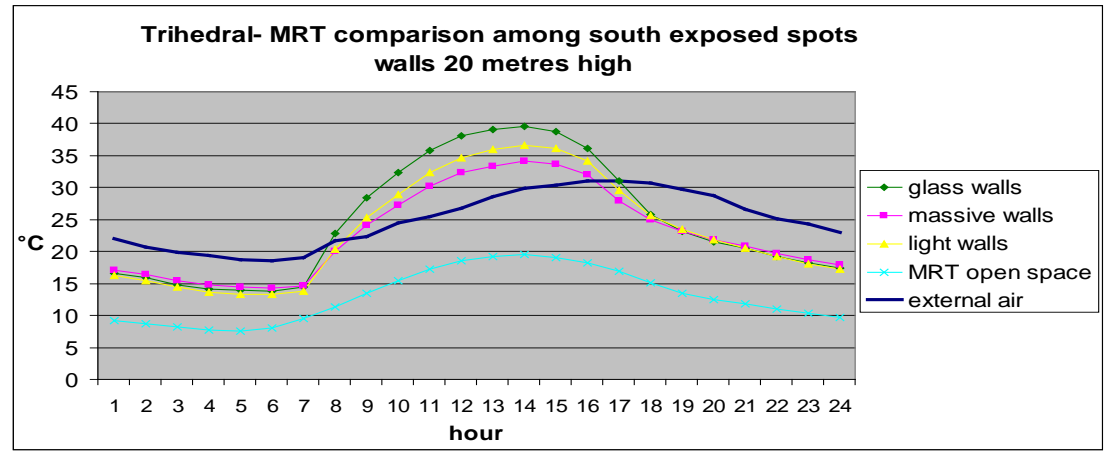

Fig.7: air temperature and mean radiant temperature (MRT) in an open space and trihedrals shape with massive light and glass wall. The point is south exposed 10 metres far from the wall $20 \mathrm{~m}$ high

Both in the dihedral and the trihedral with a glass wall the MRT is higher than in massive and light walls During the day, especially between 8 a.m. and 5 p.m. the MRT with glass wall is maximum $3{ }^{\circ} \mathrm{C}$ higher than in the light wall and till $5{ }^{\circ} \mathrm{C}$ than in the massive wall(fig.6, fig.7).. The farther we move from the wall the lower the surface difference will be; this is due to different wall materials. 10 metres far from the wall the differences are insignificant.

When the wall height decreases also the surface temperature decreases and consequently the MRT too. Differences of temperature between a wall 4 metres high and another one 20 metres high are about $4-5^{\circ} \mathrm{C}$ for every orientation (fig.8, fig.9). By comparing MRT of dihedral and trihedral with MRT in open field - with only pavement- the contribution is clearly evident. For instance at 2 p.m. a south oriented dihedral with the glass wall 20 metres high has the MRT $20^{\circ} \mathrm{C}$ higher than MRT in open field as the MRT in the configuration with glass wall 4 metres high is $7^{\circ} \mathrm{C}$ higher than one in open field.

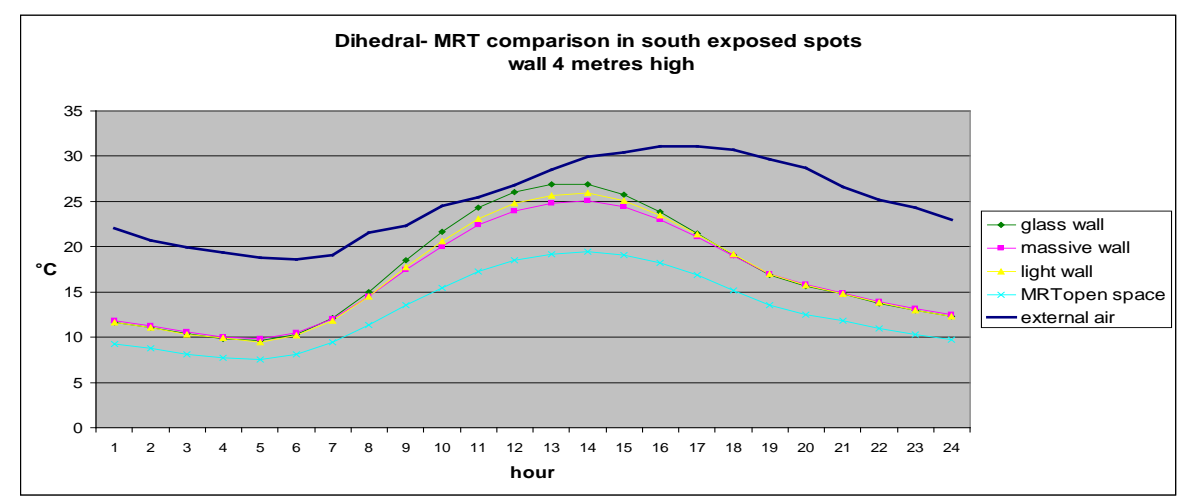

Fig.8: air temperature and mean radiant temperature (MRT) in an open space and dihedrals shape with massive light and glass wall. The point is south exposed 10 metres far from the wall $4 \mathrm{~m}$ high

It is possible to observe same differences in the other orientations even though temperature trends are different.

The MRT in the dihedral with the north oriented wall is always under the air temperature because it isn't never reached by solar radiation. The one with west oriented wall is the worst because of the large amount of solar radiation that reach the wall. 


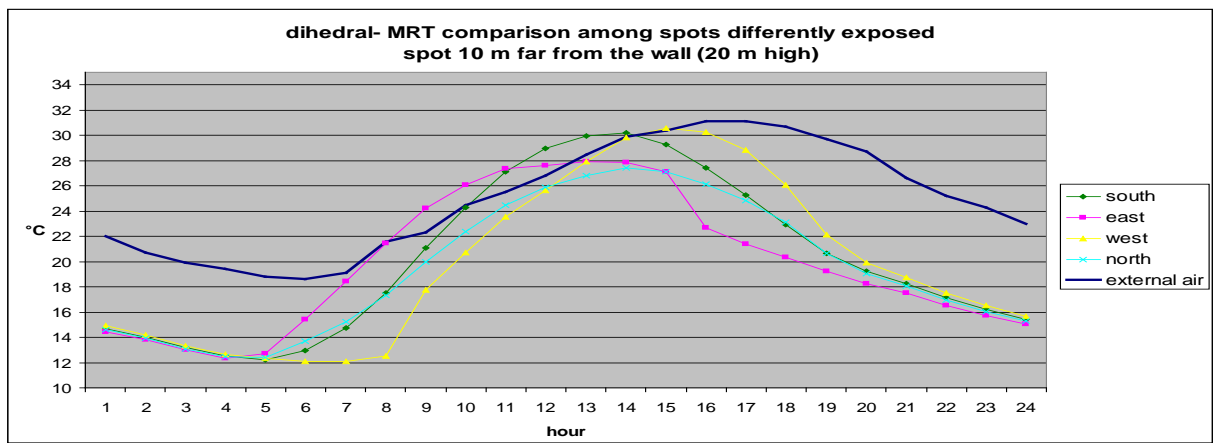

Fig.9: air temperature and mean radiant temperature (MRT) in an open space and dihedrals shape with massive wall. The points are south east and west exposed 10 metres far from the wall $20 \mathrm{~m}$ high

\subsection{Thermal comfort}

Finally a thermal comfort analysis was carried out to define configurations environmental performance in terms of people well-being. Surface temperature and MRT parameters are only a part of urban space configurations used to evaluate environmental performance. In order to evaluate thermal comfort we need to "close" this configuration by considering the sky view factor and the sky temperature. Thermal comfort was considered in terms of PET. With this evaluation it is possible to see any changing in people behaviour when they walk on a street like a "belvedere", for instance, or when getting close to a square corner. Graph reported below considers the dihedral and trihedral with facing walls 20 metres high and the analysed position 10 metres far from the wall.

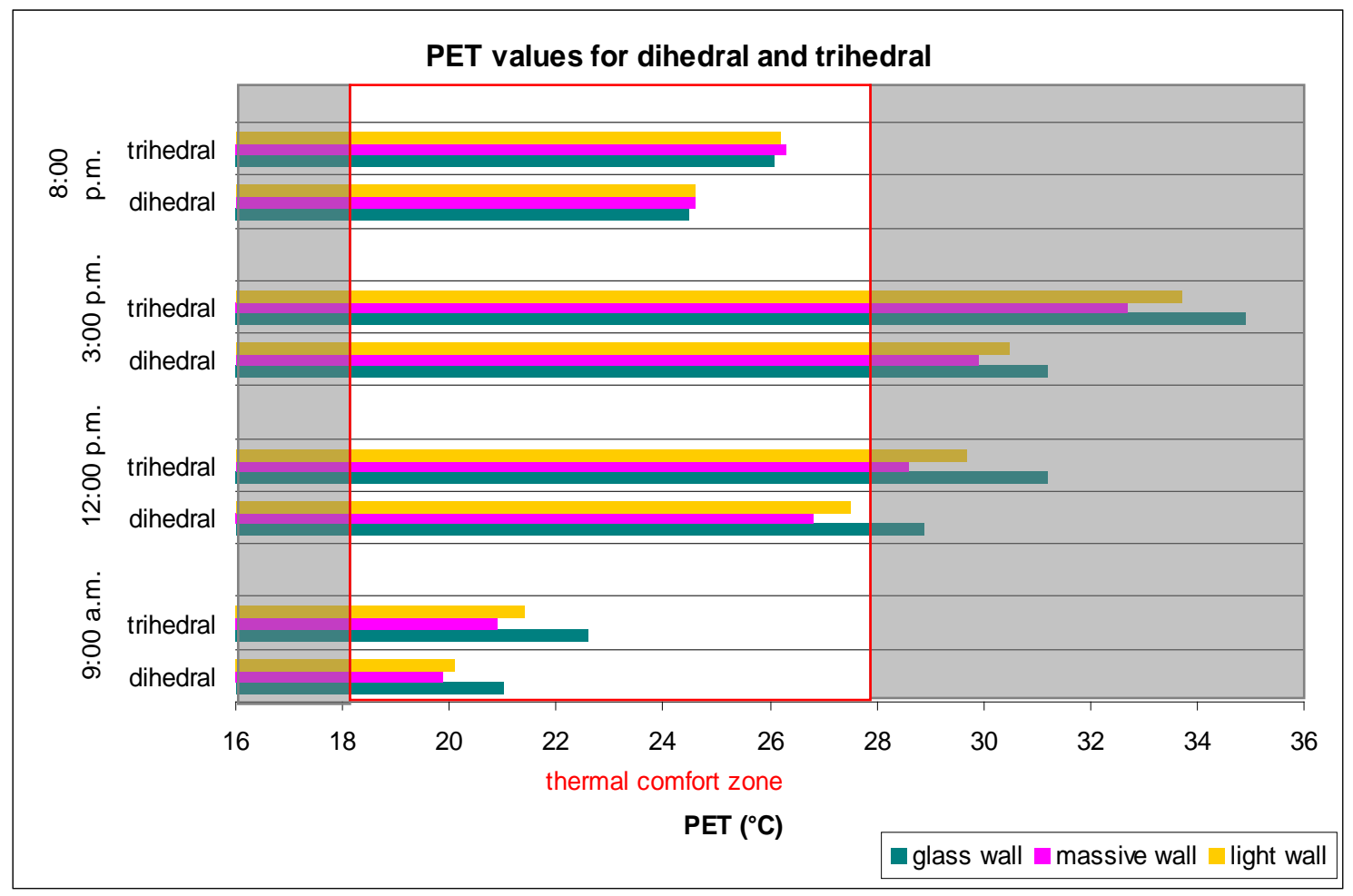

Fig.10: PET of the south exposed dihedral and trihedral with glass, massive and light wall.

For the trihedral we have the same trends of the dihedral but at mid-day and early in the afternoon PET is about $4^{\circ} \mathrm{C}$ higher then in dihedral. It is strongly recommended not to use glass wall and to be careful with the light wall too. Massive structures should be preferred.

According with the previous analysis west oriented configurations have the worst comfort conditions due to the incident radiation on the facades in the hottest hours of the day. 


\section{Discussion and conclusion}

Lot of investigation have been done considering performance of materials in terms of surface temperature. The target of these researches are mainly focused on the heat island effect [6] [7]. According to this it would be easy to have simple conclusions on the choice of the best performing urban material. Nevertheless we need to clarify possible misunderstandings.

As we have seen, during a sunny day the surface temperature increases as the albedo decreases; in other words dark colours correspond to higher temperature and vice versa.

Clear and smooth materials like the marble have surface temperature are similar to the air temperature thus they behave as they are in shadow. One of the most popular strategies to reduce the heat island effects consists of using clear materials because they don't heat and reflect solar radiation. Nevertheless some problems are faced by using clear materials and when considering the idea to white as much as possible the urban surface. Problems can be the dazzling and the visual discomfort in addition to problems related to the urban traffic.

The other issue is related to the thermal comfort. The solar radiation reflected from a clear surface, like the marble, can be easily redirect to a space user. In the heat balance we have the surface temperature (as MRT) with the whole radiation including the reflected one. It's true that the marble absorbs $20 \%$ of radiation and its surface temperature is always quite low, but we cannot ignore that the $80 \%$ go back to the environment and can hit other urban surface on the space users. Material choice has to be done by keeping in mind all the elements trying to combine the "bad" material in terms of thermal comfort, with cooling strategies, like shading devices or water cooling system. A Thermally positive material surfaces temperature should be close to the air temperature during the day, with surfaces temperature similar to the surfaces temperature of materials always shaded.

\section{References}

[1] Scudo G., Dessì V., Rogora A., "Evaluation of radiant conditions in urban space" In: Designing open spaces in the urban environment: a bioclimatic approach. Ed. CRES, Athens, 2004

[2] Dessì V., Progettare il comfort urbano. Soluzioni per un'integrazione tra società e territorio, Napoli, Sistemi editoriali Se, Esselibri. Napoli, Esselibri, 2007

[3] Antoine M.-J, Groleau D., "Assessing solar energy and environmental variables in urban outdoor spaces: a simulation tool", in: Rebuild the European cities of Tomorrow: Shaping our European cities for the 21st Century. Proc. of the 2nd European Conference, ETA, Florence, 1998

[4] Doulos L., Santamouris M., Livada I., "Passive cooling of outdoor urban space. The role of materials", in: Solar Energy n ${ }^{\circ} 77$, Elsevier, 2004

[5] Santamouris M., "Appropriate materials for the urban environment" in: Energy and climate in the urban built environment. Asimakopoulos D.N. et alii, Mat Santamouris ed., 2001

[6] Akbari H., et al., 1992 Cooling our community. A guidebook on tree planting and light coloured surfacing, EPA, Lawrence Berkeley Laboratory, 1992

[7] Akbari H., Menon S., Rosenfeld A., "Global cooling: effect of urban albedo on global temperature". In: $2^{\text {nd }}$ Palenc Conference, Santamouris Wouters ed., Athens, 2007 